\title{
New approach for the elucidation of the phenomena involved in the operation of vegetable oil extraction presses ${ }^{\text {th }}$
}

\author{
Patrick Carré* (D) \\ Terres Inovia, DTVG, Pessac, France
}

Received 24 June 2021 - Accepted 28 November 2021

\begin{abstract}
In a context where the search for naturalness, the need to reduce the carbon footprint and the development of a decentralized crushing sector are intensifying, mechanical extraction is a technology that is regaining major importance for the industry. The performance of this technique remains far below what is desirable, while the understanding of the main phenomena involved in screw presses remains insufficient. This article, after a brief presentation of the state of the art of this discipline, presents a new model centered on the notions of pressure generation and plasticity. According to this approach, plasticity can account for parameters such as the water and oil content of oilseeds, their temperature, and their possible dehulling. Plasticity in turn would explain both the compressibility of the cake and its ability to resist the thrust of the screws, and consequently to generate pressure or to creep or flow backward depending on the geometry of the screw and the cage. The model must also incorporate the notions of compression velocity, friction, and the complexity of the interactions between these parameters and the impact of the succession of screw segments and cone rings. It has been built on observation and experience and gives an understanding of the need to work simultaneously on the conditioning and geometry of the presses to achieve improved performance in terms of energy, efficiency, and reduction of the temperatures experienced by the proteins and oils
\end{abstract}

Keywords: screw geometry / unidirectional pressing / compressibility / plasticity / pressure generation

Résumé - Nouvelle approche pour l'élucidation des phénomènes régissant le fonctionnement des presses à huile végétale. Dans un contexte où la recherche de naturalité, le besoin de réduire l'empreinte carbone et le développement d'un secteur de la trituration décentralisée s'intensifient, l'extraction mécanique est une technologie qui retrouve une importance majeure pour l'industrie. Les performances de cette technique restent très en deçà du souhaitable alors que la compréhension des phénomènes en jeu dans les presses à vis reste insuffisante. Cet article, après une présentation succincte de l'état de l'art de cette discipline, présente un nouveau modèle centré sur les notions de génération de pression et de plasticité. Selon cette approche, la plasticité permet de rendre compte de paramètres tels que la teneur en eau et en huile des matières oléagineuses, leur température, et leur éventuel décorticage. La plasticité à son tour expliquerait à la fois la compressibilité du gâteau et sa capacité à résister à la poussée des vis, et, par conséquent, à générer de la pression où à fluer vers l'avant ou refluer en fonction de la géométrie de la vis et de la cage. Ce modèle doit également intégrer les notions de vitesse de compression, de friction ainsi que la complexité des interactions entre ces paramètres et de l'impact de la succession des éléments de vis et des bagues de restriction. Il a été bâti sur l'observation et l'expérience et permet de comprendre la nécessité de travailler en même temps sur le conditionnement et la géométrie des presses pour atteindre des performances améliorées en termes d'énergie, de rendement et de réduction des températures subies par les protéines et les huiles.

Mots clés : presses à vis / pressage unidirectionnel / compressibilité / plasticité / génération de pression

\footnotetext{
Contribution to the Topical Issue "Technological challenges in oilseed crushing and refining / Défis technologiques de la trituration et du raffinage des oléagineux"

* Correspondence: p.carre@terresinovia.fr
} 


\section{Introduction: improving the performance of mechanical extraction, a necessity for the emerging sector of decentralized crushing units}

For the last twenty years, there has been a renewed interest in France for solventless crushing in small crushing units. These units are generally driven by the will of local actors, often agricultural cooperatives (e.g., $\mathrm{COC}^{1}$, Terres du Sud ${ }^{2}$, $\mathrm{UCAL}^{3}$ ), but also of private operators whose objective is to produce traced oilcake to supply a local animal feed market. The growth of organic farming is also a driving force behind this expansion, as this production method prohibits the use of petroleum solvents in the processing of oilseeds. All these new actors represent about $10 \%$ of the national crushing capacity. Figure 1 presents the history of this evolution and shows a certain evolution of the progression with the beginning of units rather dedicated to the crushing of rapeseed which saw the gradual arrival of units dedicated to soybeans and cakes from organic farming and the more recent arrival of multipurpose units and units crushing sunflower. The last part of the figure presents the foreseeable evolution of capacities considering public information and project likely to start during next years.

The need for local actors to invest in crushing tools is part of a context of changing demand from the animal sectors for production under a sign of quality through compliance with increasingly stringent specifications for feed consumed by livestock (Le Cadre et al., 2015). These requirements aim at: non-GMO character, non-deforestation, fairness of the production chains, in some cases, national production of the feed, sustainability of the production chains, absence of contact with petroleum solvents (Demarco and Gibon, 2020). The oil market is less targeted by these approaches because edible oil represents a lower budget for the consumer than animal products (meat, eggs, dairy, etc.). Furthermore, consumer habits are more oriented towards refined oils as far as seed oils are concerned (Gunstone, 2011). Refining trivializes these oils so that consumers are less likely to accept paying the cost of a differentiation that will remain difficult to perceive (Turkay and Gurbuz, 2013). It should be noted that the status of the standard solvent extraction process is under threat due to questions about the harmfulness of hexane and society's increasing rejection of the "overprocessed food" with which this process is associated (Carré, 2021).

The solventless crushing units have capacities that vary from a few thousand tons per year for the smallest (generally in the organic sector) to more than 250,000 tons per year for the largest, which is an exception in this typology since its birth was motivated by the production of biodiesel. They all use purely mechanical extraction, but can use quite different technologies, ranging from cold pressing (CP), pressing after cooking $(\mathrm{PaC})$ and double pressing (PCP: cold pressing

\footnotetext{
https://www.centreouestcereales.fr/internet/filieres-amp-metiers/ centre-ouest-cereales-industries/1-unite-de-transformation-a-chalan dray-1064.aspx.

2 https://www.groupe-terresdusud.fr/acteur-economie-locale/nosmarques/soja-press.

${ }^{3} \mathrm{http}$ ://www.ucal.coop/lancement-projet-ucal-proteines/.
}

followed by thermal conditioning and a second pressing). Their performance in terms of residual oil in rapeseed meal is in the ranges $9.9-16.3 \%, 9.7-15.7 \%$ and $8.7-13.5 \%$ oil $/$ dry matter respectively for $\mathrm{CP}, \mathrm{PaC}, \mathrm{PCP}$ (rapeseed). Generally, the oilseeds that are crushed with a thermal treatment offer fairly dry meals between 1.2 and $8.0 \%$ of water. For CP cake, the range is 7.3 to $11.9 \%$ water. In comparison, solventextracted oil cakes have an average of $2.8 \%$ oil on DM and $11.5 \%$ water (personal data and data from Terres Inovia quality surveys).

It can therefore be noted that the performance in terms of de-oiling efficiency is not satisfactory, because of average residue values above $10 \%$, even in PCP, and because of a high variability is observed regarding the oil residues and proteins solubility. The level of these performances justifies a research effort to reinforce the economic competitiveness of the decentralized oil-mills sector. The objective of this paper is therefore to initiate a reflection on the operation of presses used to extract oil mechanically. The aim is to better understand the limitations of their performances and to propose improvements for higher yields without capacity losses and without quality degradation due to process temperatures. After reviewing the literature on mechanical extraction and its limitations, we propose a new approach to the operation of screw presses that aims to understand how pressure is generated as a function of material rheology and press geometry. The importance of plasticity is widely discussed and justified on the basis of observations. Some cake behaviors rarely discussed in the literature such as slipping are described and explained.

\section{State of knowledge: limitations of available parametric studies and inadequacy of work on unidirectional compression}

It is a common observation in the scientific literature dedicated to the study of mechanical oil extraction that there is quite a small amount of work on the subject and that the topic is rather poorly understood (Bogaert et al., 2018; Bako et al., 2020). After analyzing numerous publications devoted to the study of oilseed pressing, our opinion is that there is quite many works that have this issue as their subject, but that few of them offer a convincing description of the different phenomena involved in determining the behavior of screw presses. In this article, we propose, after a quick presentation of the state of knowledge, to give a description of the operation of the presses expressed in common language, which aims to report of the complexity of the observed phenomena.

\subsection{Limitations of parametric studies}

According to a relatively extensive bibliographic exploration about the mechanical extraction of vegetable oils involving the analysis of 212 articles (see Box 1), we found relatively few articles addressing the understanding of the operation of screw presses. Only 15 were modelling articles trying to give a general model not depending on the experimental conditions. In most case, we have parametric 
studies that are working on finding an optimum of a given system comprising a specific press and an oil-bearing material. From these works, it is not possible to make accurate prediction about the performances of other systems.

\section{Box 1. Bibliography analysis}

Used database were google scholar and, SCOPUS. Keywords used were "mechanical extraction oil", "oil expression", "press oil", "screw extraction oil". The selection started to 1987 up to the current period. An initial selection of about 200 articles was screened, leading to set aside 108 articles (articles concerning the effect of extraction on the properties of the products, effect of pre-treatments like enzyme digestion, comparisons between mechanical extraction with other extraction methods, etc.). During the analysis work new articles were found in the bibliography included in the papers resulting in a new list of 212 articles. Then articles regarding oil point, twin screw extrusion, reviews, and generalities were set aside resulting in a shorter list of 158 articles. Among these articles, we distinguished the articles in which the authors proposed a modeling of the operation from those which could be considered as optimization works where no general principles were used to characterize the press operation. An excel table is given in supplementary material with the list of the examined publications. A second table is dedicated to articles reporting on modelling. It lists the articles that actually deal with the modelling of continuous pressing and indicates how the rheology of the material is considered in the model. Despite the great interest of these works and the merit of their authors, no proposed model has so far succeeded in combining all the requirements presented in this article, at least according to this analysis.

These studies are most often the result of an experimental design, which aims at measuring the influence of parameters related to the material, preparation, conditioning, and operating parameters of the presses on extraction performances. For the material, these parameters are moisture content (Evangelista and Cermak, 2007; Martínez et al., 2012), seeds variety (Olayanju et al., 2006) or seed composition (oil content [Rombaut et al., 2015], fiber content [Mridula et al., 2019]), dimensional characteristics (Fadhlullah et al., 2015) or seed maturity stage (Ibrahim et al., 2017), sometimes even, selection traits such as oil composition (Pedretti et al., 2019). Preparation concerns dimensions such as storage conditions, possible milling (Venkitasamy et al., 2014), flaking (Vadke and Sosulski, 1988), dehulling to a greater or lesser extent (Zheng et al., 2003), extrusion (Patil and Ali, 2006; Evangelista, 2009). More rarely, pulsed electric fields (Sarkis et al., 2015), ultrasound (Zdanowska et al., 2019), controlled instantaneous relaxation (Bouallegue et al., 2016) may be used. Enzymatic pretreatments have also been the subject of several studies (Soto et al., 2007; Bargale et al., 2000). Investigations on conditioning focus on cooking, which can vary in terms of duration, temperature (Wiesenborn et al., 2001; Singh et al., 2002a), initial and final moisture content (Singh et al., 2002b; Moreau et al., 2005). The cooking method may also have been investigated (microwave treatments: Uquiche et al., 2008). With respect to the press, experimenters observe the effect of press rotation speed, dimensional characters such as the size of the cake outlet (Deli et al., 2011; Karaj and Müller, 2011; Liu et al., 2017), the ratio of volumes generated by the first screw segment to that of the last (Fakayode and Ajav, 2019), screw pitch, cage and/or shaft preheating (or cooling) (Naeem et al., 2017), feed rate (Akinoso et al., 2009), cage bar spacing. Some authors have also investigated the effect of the press start-up mode, especially when blockage problems occur when cold (Tostenson et al., 2004). There is also work on modified twinscrew extruders to perform oil extraction (e.g. Dufaure et al., 1999; Kartika et al., 2005) and some publications on the performance of twin-screw presses (Li et al., 2007, 2010; Shilong and Xiefang, 2011).

The variables observed are the material balance, the oil content of the press-cake, the flow rate of the press, the power demand of the engine. More rarely, we will find data on the pressure measured on the cage, the sediment content of the oil, the quality of the oil (acidity, oxidation, oxidative stability, phosphorus content, color), the solubility of proteins in the cake.

The problem with all these studies is that they are usually limited to noting that within the framework of the system studied, an optimum is observed for this or that combination of parameters without these results being generalizable or extrapolated to another situation. In fact, we note the existence of interactions between parameters without being able to explain these interactions or to say why the optimums obtained are different between two publications on neighboring systems. An example of divergent findings on the effects of water can be found in two studies using the same Komet 59G press. The first conducted by Martínez et al. (2012) was on sweet almonds kernels (Prunus dulcis), the second operated by Mridula et al. (2019) on dehulled flaxseed (Linum usitatissimum). The almonds underwent coarse grinding and then sieving, so that the raw material had a particle size between 2.4 and $4.8 \mathrm{~mm}$. The initial moisture content was $4.5 \%$ and the oil content was $53.1 \%$ on dry matter. The flaxseed was dehulled by passing it through a rice polishing machine and then vacuuming the hulls and sieving to remove the fines. Whole seeds were then reincorporated in varying amounts to establish a range of hulling rates with oil content from 40 to $52 \%$. In both cases, the moisture content was adjusted to a range of $4-12 \%$ for almonds and $6-10 \%$ for flax (lower moisture contents were not possible due to press blockage). In the case of almonds, the material was preheated before pressing at temperatures of 20 to $60^{\circ} \mathrm{C}$, while in the case of flax, the press head was maintained at temperatures of 80 to $120^{\circ} \mathrm{C}$ by a heating resistor. In terms of results, we observe an improvement in the extraction yield of the almonds from a water content of 4 to $8 \%$ and then a quasi-steady performance by going towards higher values of water content. The opposite is observed in the case of flax where the best yield is obtained for $6 \%$ water and decreased continuously until 10\% (Fig. 2a). Regarding the effect of temperature, with almonds, an optimum is observed at $40{ }^{\circ} \mathrm{C}$ for the optimal water content of $8 \%$. In the case of drier almonds kernels. However, the higher temperature is the most favorable (Fig. 2b). For whole 
France hexane-free oil mills cumulative capacities

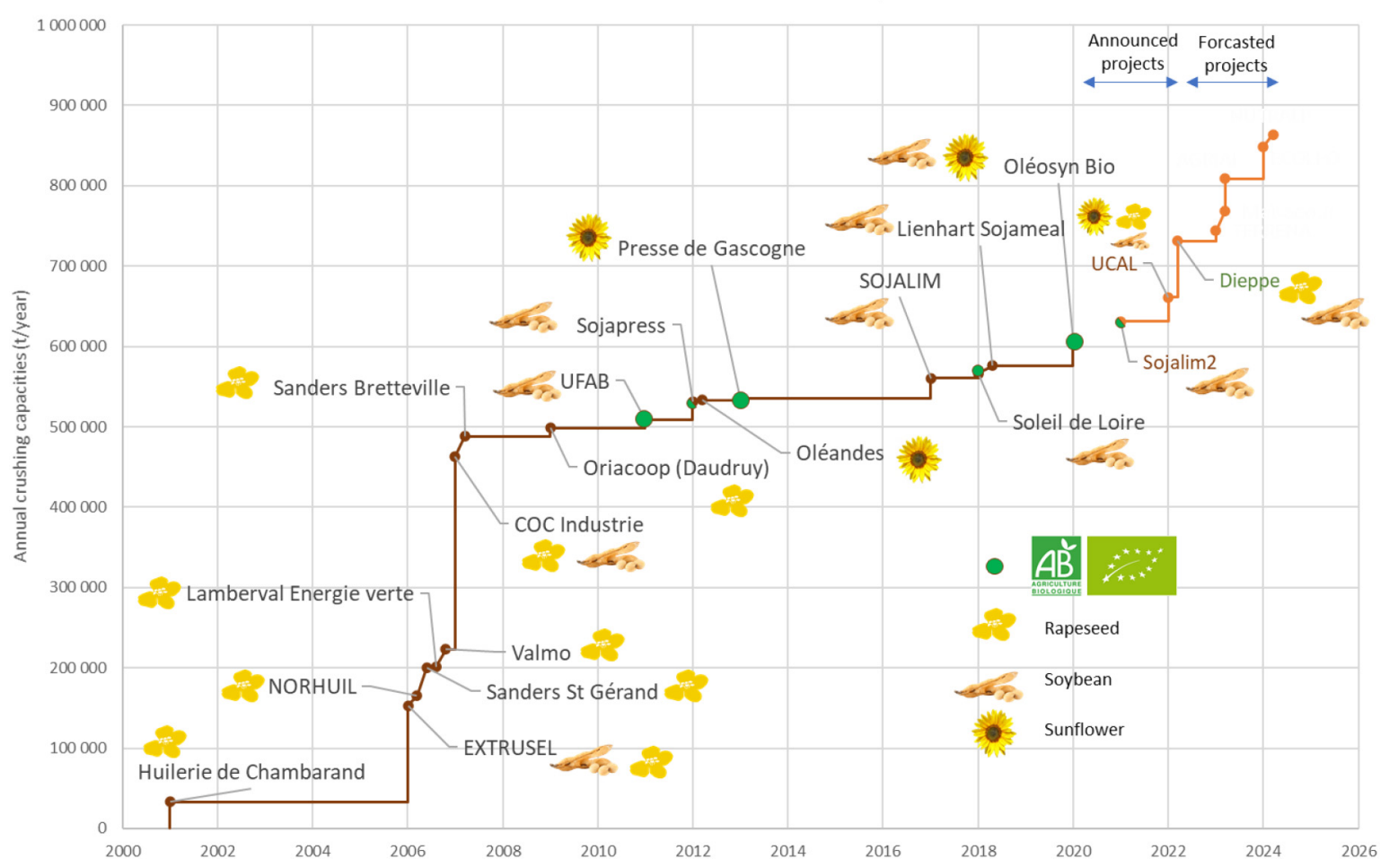

Fig. 1. Progression of crushing capacities in the "solvent-free" mode in France from 2000 to today and foreseeable future. The green dots indicate the capacities dedicated to the "organic" sector.
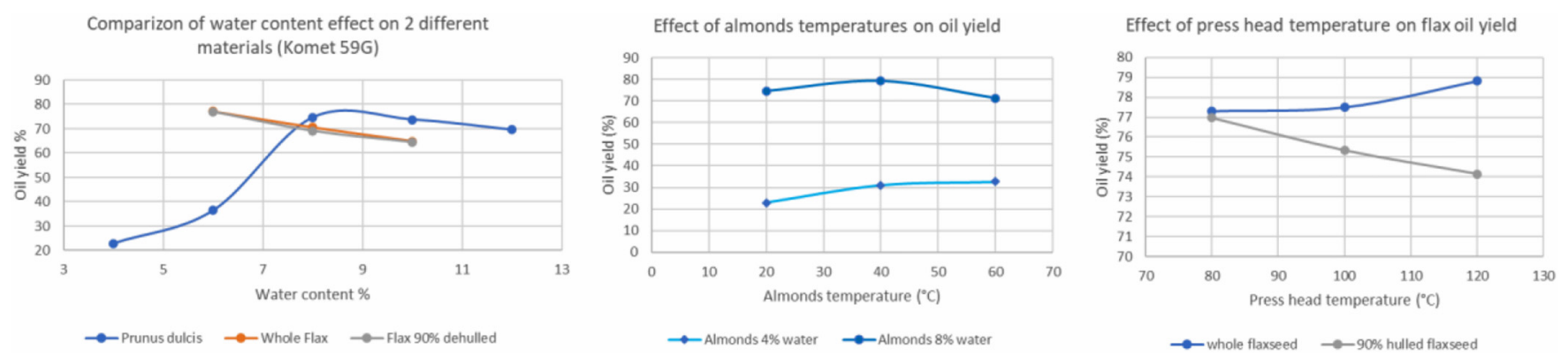

Fig. 2. Effect of water content and temperature on oil yield reported by Martínez et al. (2012) and Mridula et al. (2019) for almonds and flax using a Komet $59 \mathrm{G}$ press.

flax, the effect of temperature is positive on yield while it is rather negative when the seed is dehulled (Fig. 2c). Our interpretation is that the compressibility of sweet almonds was limiting and increasing the water content was necessary to increase plasticity. Increasing the temperature of dry almonds also partially improved plasticity and oil yield. In the case of flax, the compressibility of the dry seeds was significant and increasing the water content was bringing excess plasticity that limited the ability of the press to generate pressure. The differential effect of temperature between whole and hulled flax suggests that for dehulled flax, there is a probable effect of excessive plasticity accentuated by temperature, whereas in the case of whole flax, plasticity while close to the optimum was perhaps still below and an increase in temperature allowed a favorable correction.

\subsection{Contributions to the study of unidirectional pressing}

In addition to these parametric studies that use screw presses, there are quite a few articles (about 20\%) that deal with unidirectional compression. Here the pressing is carried out in piston presses and their objective is rather to characterize the compressibility of the matrices in connection with the preparation and conditioning parameters just listed. For a significant part, these articles are similar to the parametric studies on screw presses and are limited to highlighting an optimum combination of parameters. However, the fact of carrying out observations in a simplified device and allowing to have a great quantity of information makes it possible to propose a modeling of the curves connecting the deformation 
and the compressive force. Such modeling can be inspired by the Terzaghi-Voigt consolidation model modified by Shirato et al. (1987). Bogaert (2017) has put together a remarkable synthesis of these approaches in her thesis. Other authors from the Czech University of Life Sciences Prague focus on describing the specific energy required for compression (Herak et al., 2010; Sigalingging et al., 2014; Kabutey et al., 2018). The first approach generally requires a constant pressure and is used to predict the time required for cake consolidation, i.e., the time required for all the oil that can be displaced under a defined pressure to complete flow. This model allowed Lanoisellé; (Lanoisellé et al., 1996) to describe the consolidation by different modules corresponding to volumes of cake more or less easy to deform. The second type of model works with a constant compression speed and measures the evolution of the force required to ensure the movement of the piston. This force corresponds to a work that can be reduced to the compressed volume to define a quantity of energy necessary to reach a given compression level. We can get an idea of the compressive resistance of the matrix.

\section{Need for a global approach considering the relations between the material and the equipment}

\subsection{Importance of pressure generation in a continuous system}

The problem is that screw presses do not work like piston presses. In the latter, the solid cannot escape, only the oil can be moved, so that the pressure is only the result of the resistance of the cake to compression. In screw presses, the cake moves almost continuously, and the pressure is not determined mechanically by the movement of a piston but by the resultant of the axial thrust of the screw and the resistance of the cake to this thrust. This resistance naturally depends on the material consistency, it also depends on the geometry of the press, that is to say the obstacles which are opposed to the advance of this cake. The simplest way to create this opposition to the thrust is to reduce the passage through which the solid must pass to advance. In the simple presses whose screw has a uniform profile, this restriction is located at the level of the outlet of the cake which is a die located in the axis of the screw. By adjusting the diameter of this orifice, a more or less important resistance to the passage of the cake can be opposed. On press models where the screw is composed of segments separated by distance rings, it is possible to play on the reduction of the volume generated by the rotation of the screw threads, it is also possible to play on the length of the distance rings between screw segments to increase the friction between the cake and the cage, it is also possible to play on the conicity of these rings to progressively reduce the available passage surface for the cake and maximize the friction against the cage (Ward, 1976; Khan and Hanna, 1983). A rarely used possibility is also to place counter-rotating screw segments sized to partially push the solid at counterflow. With these press designs, it is often possible to operate the outlet port by changing the gap between the rotating and stationary parts. This possibility is especially useful on the small and short presses, it of lesser utility on the large industrial presses.
To simplify the issue, we can say that high pressures are needed to maximize the extraction of oil and that to reach high pressures, we must be able to produce a situation where the solid resists the thrust enough to generate this pressure without going to a blocking situation where the screw can no longer overcome this resistance force. For the sake of simplicity, we can postulate that this resistance to thrust is similar to the resistance to compression, which is itself similar to the resistance to deformation and therefore to creep.

\subsection{Impact of the material characteristics}

\subsubsection{Compressibility/plasticity}

There is a fundamental and insufficiently understood contradiction here between the need to act on the rheology of the solid to give it a certain resistance to compression, itself necessary for the generation of pressure, and the opposite need to reduce this resistance to compression to facilitate and maximize the expression of oil. Water and temperature are plasticizers that tend to reduce the energy required for compression. The effect of cooking before mechanical extraction is to affect both the water content and the temperature of the material and therefore produce both a reduction and an increase in compressibility. From this point of view, it is easier to understand why the results of parametric studies are contradictory and do not allow a clear explanation of the phenomena involved. However, this way of posing the problem is rarely put forward and used. Ward (1976), in an article, which is otherwise remarkable for the precision of the analysis he gives of the operation of presses, does not address this notion of machine-material interaction. Rather, his approach is to indicate the differences he observes in the behavior of different oilseeds without going so far as to attempt to draw a generalization. Bogaert (2017) in her thesis took a close look at different approaches to modeling batch pressing in an attempt to relate the compressibility characteristics of materials to their behavior in a screw press. Among the different published models, she selected the work of Murase et al. (1987) and Shirato et al. (1987) adapting the Terzaghi-Voigt approach, itself based on the study of deformation at constant pressure, to follow the compressibility and behavior of a material subjected to a variable pressure. According to her, Shirato, proposes in particular a relation between pressure on the one hand and press geometry combined with a compressive strength characteristic on the other hand. Unfortunately, the experimental work carried out during her thesis did not go as far as using this relationship. Kabutey et al. (2019) presented a slightly different approach where material characterization is done by measuring the energy required for compression by attempting to relate measurements made on a piston press to the operation of a Farmet FL200 screw press. Based on measurements made with this piston press, where they varied the diameter and the filling level as well as the dimensional characteristics of the screw, they were able to calculate a range of predictive pressure values without being able to validate these theoretical values by experiment. Although this attempt seems interesting, it seems to us that it was not considering the sliding phenomena, which, according to us, probably have the effect of limiting the pressure value really reached. 


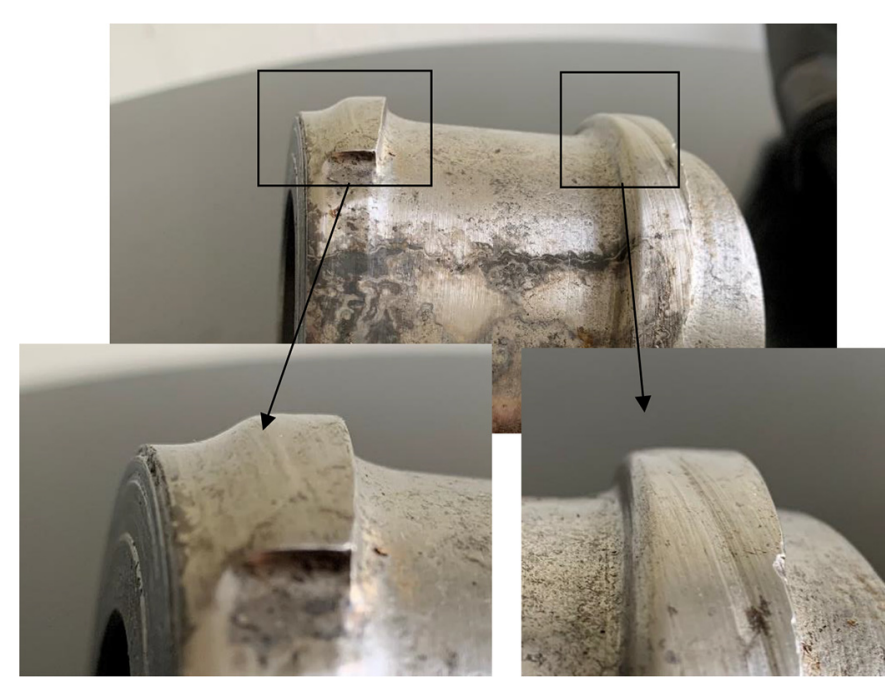

Fig. 3. Photograph of a badly worn screw segment. The enlargement on the left shows the screw thread in the terminal part while the enlargement on the right shows the thread in the upstream part of the screw. Note: the thrust surface is much less vertical in the eroded part of the thread.

Following Bogaert (2017) and Kabutey et al. (2019), we believe that it is necessary to consider the parameters influencing the rheology of the oleaginous material in the dimension "compressibility" to allow a more homogeneous, predictable, and reproducible account of the essence of the behavior of the matrices in presses. Indeed, this concept of compressibility is probably the result of several factors such as the resistance of cell walls to deformation and rupture, as well as the flow of oil that depends on its viscosity and the permeability of the cake, which in turn may depend on the pressure that by causing the collapse of the capillary network can paradoxically block the oil in the solid (Ward, 1976). The compressibility can also be influenced by the cooking of proteins that are native in the form of compact protein bodies and once coagulated can take a spongier texture, opposing less resistance to compression. Coagulation of oleosins probably also has a release effect by allowing coalescence of the oleosomes. The duration of exposure to heat may still have the effect of moving the oil from the inside to the outside of the cells where the obstacles to its mobility are weakened by the simple effect of molecular agitation.

\subsubsection{Impact of friction}

It is likely that this notion of compressibility is not sufficient to fully characterize an oil-bearing material. It is likely that a friction characteristic is necessary to explain differences between products of close compressibility. However, we do not believe that friction is as decisive as claimed by several authors (Singh et al., 2004; Uitterhaegen and Evon, 2017; Mridula et al., 2019) the latter of whom do not consider the notion of compressibility. Friction between the cake and the cage plays a role in preventing the rotation of the material with the screw, it is also responsible of the temperature generation, and depends not only of the material composition but also of steel characteristics (screw and bars) and of the design of the cage.

\subsubsection{Impact of cohesivity}

Another factor that may be involved is that of adhesion capacity between particles. In the press, the solid material changes from a particulate state (isolated seeds, pieces of seeds) to a continuous state (cake). The ease with which the solid can agglomerate probably influences the behavior of the press since what allows a screw to exert axial thrust is the resistance to rotation of the solid due to the friction between it and the cage on the one hand and between the particles themselves on the other. Once the solid is agglomerated, it is much more difficult to follow the rotation of the screw because it forms a continuum pressed against the cage by the pressure and therefore, much less sensitive to the rotational thrust. We formulate this hypothesis according to the observation made in industrial production conditions where problems of functioning can sometimes be solved by the contribution at the entry of the press of a very small volume of water in the form of dripping. It is thus possible to go very quickly from an operation where the material passes through the press with poor oil yield and where the solid comes out as a powder rather than a cake to a significant increase in the production of oil and the formation of a hard and coherent cake after this water supply. The presence of liquid water on the surface of the particles would allow them to stick to each other and would facilitate the caking with favorable consequences to the expression of oil.

\subsection{Importance of press geometry}

\subsubsection{Thrust capacity}

In addition to the characterization of the oleaginous material, it is necessary to characterize the geometry of the press. For this, it would be appropriate to characterize on the one hand, its capacity of thrust and on the other hand its resisting capacity to the cake's forward motion. For the thrust capacity, we suggest taking into account the surface of the screw threads in contact with the cake, corrected by the angle they form with the screw axis. This capacity must also consider the distance between the thread and the cage and, for worn threads, the angle formed between the pushing surface and the perpendicular to the axis (Fig. 3). These characteristics determine the possibility that a flow of solids can flow back towards the rear of the thread and contribute to the sliding phenomenon described below. This phenomenon is typical of worn or poorly dimensioned screws. It should also be noted that in the terminal part of the screws, if the diameter of the core becomes large, the thrust surface is reduced with the effect of limiting its effectiveness. Another correction to be introduced concerns the axial distance of the thread in relation to the screw exit point. We believe that the thrust is not equivalent on the whole circumference. We base this on the observation that the wear of the screw segments is always more pronounced in the exit zone than in the entry zone. As an example, Figure 3 is a photograph of a very worn screw segment where we can see that at the exit of the screw, the pushing face of the thread has been completely eroded and that this state of wear is much less pronounced in the anterior part. We can also see that the height of the thread in the exit area is almost $2 \mathrm{~mm}$ lower than the height of the anterior part.

Figure 4 presents the analysis of the operation of a screw pressing cold rapeseed and to visualize the volumes generated 

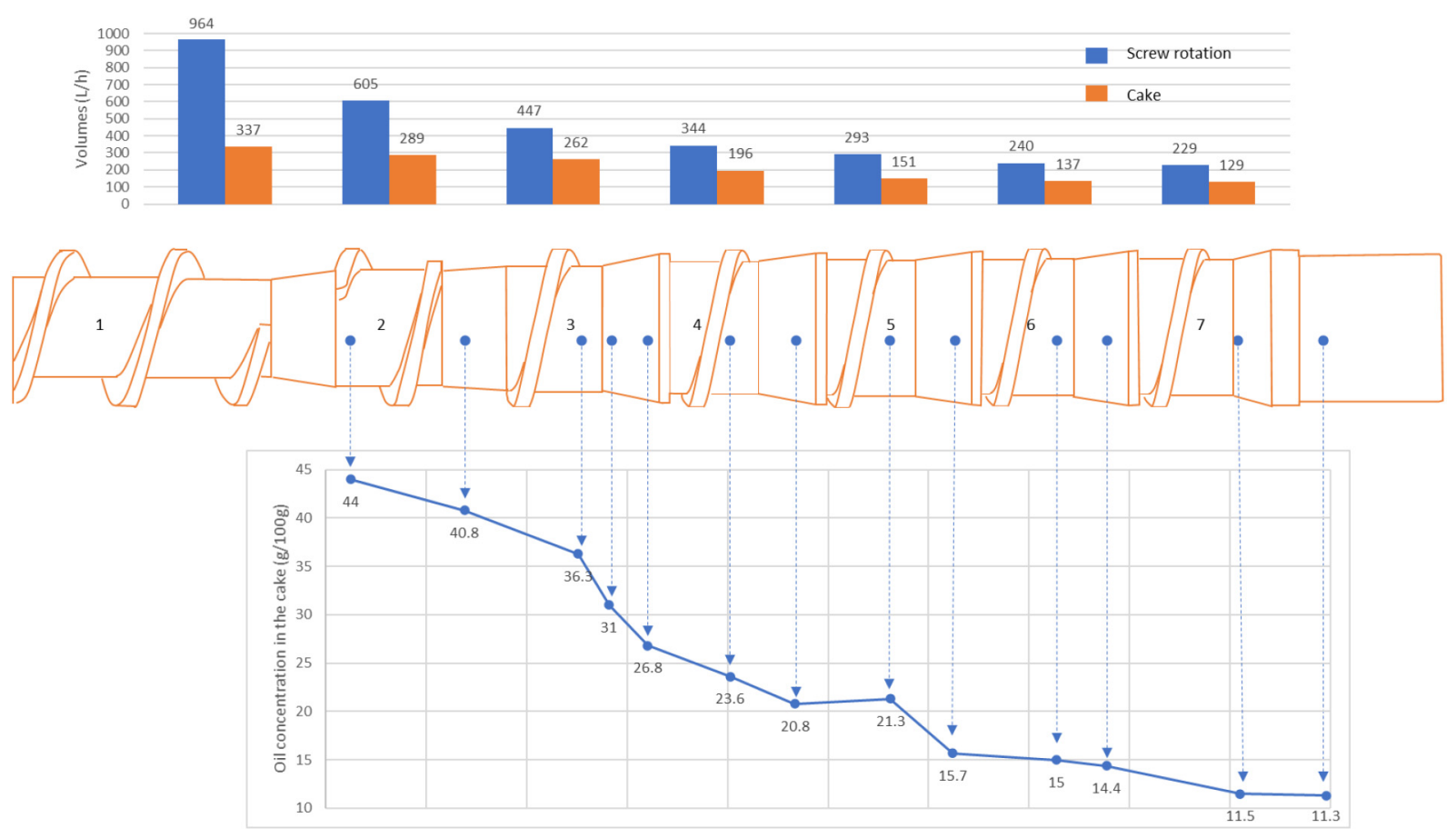

Fig. 4. Upper part: comparative evolution of the volume generated by the rotation of the screw segments and the volume of cake displaced. Middle part: diagram of the screw and location of the samples taken. Lower part: evolution of the residual oil content in the case of a cold pressing of rapeseed. Measurement carried out by stopping the press under load to quickly open the cage and take localized samples.

by the rotation of the segments of screw and the volumes of cake actually moved and the evolution of the oil content of the cake during its progress. The volumes generated by the screw are evaluated according to the respective diameters of the core of the screw and the cage, the pitch of the screws and the rotation speed. The volume displaced is evaluated based on the flow of cake measured at the exit of the press assigned a density 1.0 for the last screw and then adding to this volume, the additional oil measured in the screws located upstream. For the first screw, it is the density of seeds that was considered. The differential between the two volumes gives an idea of the slip. This one decreases gradually since it passes from a ratio between the volumes of 0.31 for the screw No. 2 to 0.56 for the screw No. 7.

The lower part of the graph shows the oil contents, which were measured after stopping the press under load and opening the cage for a localized sampling. It shows that the screw 3 produces a significant de-oiling while the screw 4 is much less effective and that the No.5 allows again a significant extraction. Then, the No. 6 seems to produce less oil than the No.7. It does not seem that the differential between volumes is a sufficient factor to explain the evolution of residual oil. Considering the diameter of the rings also does not explain why the fourth and sixth segments were less productive than the previous and subsequent segments. Furthermore, no areas were observed where the screw was incompletely filled. On the other hand, it was possible to observe strata corresponding to the smoothing of the cake made by the friction of the end of the thread. The distance between strata should make it possible to measure the distance traveled by the cake at each rotation at the level of the cone rings.
To come back to the question of pressure variations during the rotation, it would be interesting to have precise information to put in relation with the differential between generated volume and real volume and the plasticity of the cake. We can indeed imagine that with a low differential, the pressure should vary less than with a high differential. In the same way, with a high plasticity, we should see a lesser variability of the pressure than in the case of a reduced plasticity.

Figure 5 illustrates the phenomenon of irregular exit of the press cake. It shows the advancement of the cake over the duration of a rotation of the screw. Seven views were taken at the exit of a French L250 press processing cold rapeseed, taken at times corresponding to an interval of $60^{\circ}$ for the shaft rotation. The arrow has been positioned to represent the same point on the cake and show its displacement. The graph in Figure $5 \mathrm{~h}$ shows that over half the rotation time, the cake advance is almost zero and that it increases in size over the second part of the rotation.

\subsubsection{Opposition capacity}

Concerning the opposition capacity of the press, it can be broken down into several compartments as described above: (a) the volume reduction generated by the rotation of the screw segments, (b) the friction between the cake and the cage, especially in the smooth segments separating two screw elements, friction to which it would be necessary to assign a coefficient related to the local pressure and finally, (c) the rate of restriction imposed by the conical rings which could be assimilated to a ratio between distances from the screw core to the cage at the cone inlet and outlet. The position of the outlet 


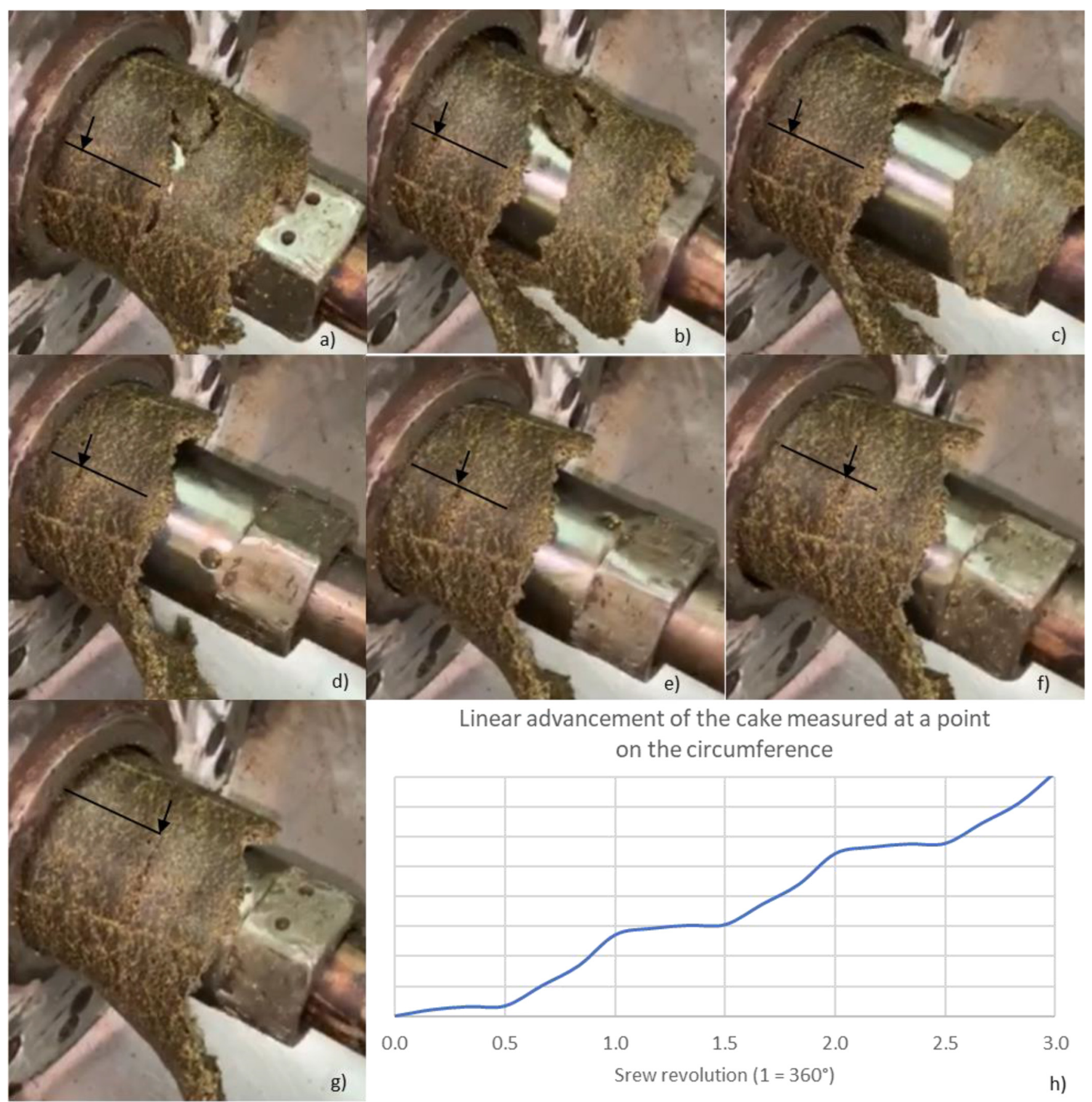

Fig. 5. (a-g) Views of the cake output (rapeseed, cold pressure) on a French L250 press. The seven views are taken during one screw rotation by increments of $60^{\circ}$; (h) cake progression as a function of the screw rotation. We notice here that for $50 \%$ of the time, the linear progression is almost null.

organ, especially the gap between the terminal part of the screw and the terminal part of the cage which determines the cake thickness could be assimilated to the same type of restriction.

\subsubsection{Effect of rotational speed}

The rotation speed is the last factor to be considered. It conditions the residence time and the kinetics of pressure rise.
Models of unidirectional compression based on the theory of consolidation highlight the need for time to allow the cake to reach the final stage where the volume stops reducing (Willems et al., 2008). The reality of continuous pressing differs considerably from this model as most presses have rotational speeds ranging from 10 to $60 \mathrm{rpm}$. The pressure varies accordingly in times between 1 and 6 seconds, and the pressure is not kept constant but varies rapidly during a revolution. The speed of the screw, however, is constant and it would seem that 


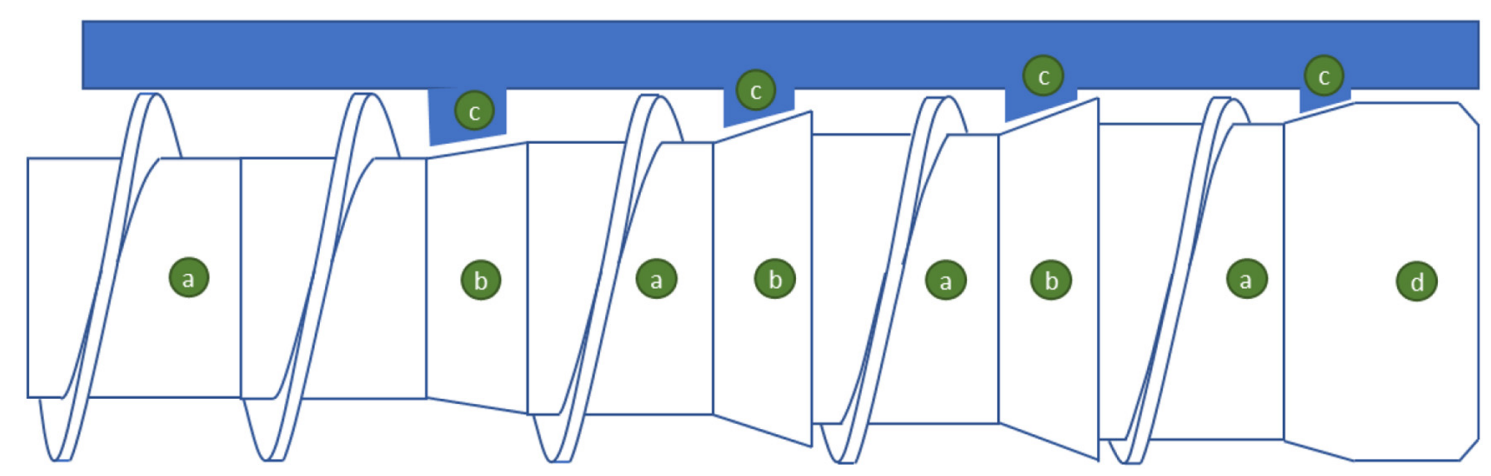

Fig. 6. Schematic representation of the screw of a press: (a) screw segments; (b) distance rings or cone rings; (c) knives; (d) end sleeve.

among the unidirectional compression models the constant speed model is closer to reality. However, the unidirectional press simulations are done at much slower speeds, which probably does not properly address the issue of material behavior under rapid compression. In our experience, rapid compression of brittle materials such as jatropha kernels can lead to no solid/liquid separation and extrusion of the mixture through the bars without de-oiling while a slow compression results in fair separation (Chapuis et al., 2014). The same type of behavior occurs when trying to cold press soybeans using a very restrictive press profile. The meal is expelled through the cage bars and the oil content of the meal remains high. The measurement of compressibility should, in our opinion, take into account the notion of compression speed and consider the speed at which the pressure can vary in a screw press. In this regard, the literature is silent. No publication to our knowledge indicates the variation of the radial pressure over the duration of a screw rotation.

\subsubsection{Role of the screw arrangement}

In order to model the movement of the solid in the press, it will also be necessary to consider the feed rate of the screw segments. As mentioned earlier, the slip rate implies that some material follows a non-axial path and therefore does not feed the screw segment downstream. As a result, some segments may be underfed and therefore incompletely loaded, which should have the likely effect of increasing their own slip rate, with the pressure differential in the screw channel being accentuated by this underfeed. A screw segment that is underloaded in this way would most likely generate a lower average pressure. Thus, it would only take one segment to be misconfigured to affect the operation of the entire downstream part of the press. In contrast, it is conceivable that when the output resistance level of a segment is not limiting, it is the incoming capacity of the next screw (i.e., its capacity to take that volume of material) that becomes limiting. From this, it follows that the relaxation of the solid at the entrance of the downstream screw will decrease which will favor the generation of a higher pressure, both in the segment considered and the one located downstream. In this case, as the pressure in this segment increases, equilibrium is probably achieved by increasing the slip, which in turn limits the incoming capacity, which is reflected in the previous screw and eventually in the first screw of the arrangement. Thus, it can be observed that by reducing the gap at the press outlet, the overall flow of the press decreases and that at the first screw segment, it is possible to observe the rotation of some of the feed flow rotating with the screw.

We can therefore consider that when the reduction of the outlet gap has no impact on the general flow of the press, it is because the press probably has a passage that is too restrictive somewhere and that it would be appropriate to reduce this obstacle to better feed the downstream parts.

It follows from this question the importance of the proper functioning of the first screw, especially when the crushed product is very rich in oil as in the case of peanuts, sunflower kernels, jatropha, walnut kernels, etc. The lack of pressure in the feed zone in conjunction with a low pressure necessary for the expression of oil causes the oil to flow back easily into the feed zone where gravity alone is not always sufficient to overcome the resistance of the cage because the passage of spaces between bars are clogged by the presence of ground kernels. In consequence, the accumulation of oil makes the friction between kernels and kernels or cage and kernels practically zero and does not allow the screw to move the solid material in the axial direction. To overcome this type of problem, it is necessary to open as much as possible the spaces allowing the oil to flow (for example by use of perforated cages with holes of 2 to $3 \mathrm{~mm}$ instead of bars) and possibly to fill the feeding area with a single or double screw (Florapower, 2021).

An unsuitable configuration can sometimes be compensated for by the fact that the excess sliding generates an excess of friction which heats the material to be de-oiled and can improve its compressibility and thus reduce the resistance to the passage of obstacles. By letting the press heat up, an improvement in performance can be achieved, often observed at the time of start-up, with a better de-oiling efficiency, capacity, and a slight decrease in power consumption when the press reaches its equilibrium temperature.

Another phenomenon can be observed when the press is underfed compared to the driving capacity of its first screw. It is a phenomenon of cyclic operation: initially, the output flow is low to zero. The pushing capacity is insufficient to overcome the resistance of the cake located in the terminal part of the press. With time, the material accumulates in the screw, gradually filling the volume of the channel. At a certain point, under the effect of the filling, the screw finds a certain capacity of thrust which is translated in a simultaneous way by a fast advance of the cake, a significant production of oil and a strong increase of the 
resisting torque calling a peak of intensity at the level of the motor. However, this phase is short-lived. Soon the amount of solids in the press decreases, so that the pushing capacity is reduced, and the cake advances resumes its slow motion. This cyclic operation is generally unstable, it can decrease if the excessive friction observed during the periods of stagnation allows to heat the press to a level reducing enough the resistance of the cake. On the contrary, it may increase if, despite the rise in temperature, the cake becomes progressively more resistant due to a lower and lower oil content. This type of problem is easily avoided by ensuring a higher screw feed rate or by reducing the rotation speed, except when the material to be pressed is hard and the feed rate cannot be increased, or the speed reduced because the current called to the motor is close to the machine limit. The recourse in this case is to act on the compressibility by playing on the water content, temperature, release of oil from oleosomes by cooking, or dehulling. Obviously, a change of the press geometry reducing the opposition strength would be a best solution when possible.

\section{Conclusion}

To summarize: from the point of view of conditioning, the efficiency of presses is above all a question of compromise between the need to generate pressure which requires resistance to thrust, thus low plasticity, and the need to preserve compressibility implying high plasticity. From the point of view of the press geometry, we will remember the importance of the phenomena of backflow and slippage, which reduce the processing rate of the presses when the opposition capacity exceeds the pushing capacity. It seems likely to us that these phenomena have a limiting effect on the pressure, even if in addition by increasing the time during which the material is subjected to friction, they allow a heating likely to improve the effectiveness of the extraction. It seems to us that the greatest attention should be paid to the geometry of the pushing surfaces, which should be designed to limit slippage and improve the transmission of the axial thrust in order to reach higher pressures and limit the unnecessary heating of the solid. Moreover, the achievement of improved performances requires to act simultaneously on the conditioning and the optimization of the press geometry because we have seen that the optimal plasticity is not the same from one press to another. Friction is also a factor requiring consideration through the choice of steels quality. It must be maximized on the cage side to avoid the cake rotation and it should be minimized on the screw side to limit unnecessary heat generation and rotational thrust.

\section{Terminology}

Screw press: device invented by Anderson in the early twentieth century for the continuous extraction of oil from oilseeds. A screw press is an Archimedean screw designed so that the material transported undergoes a progressive compression due to the reduction of the volume available for the passage of the solid and allowing the flow of oil through a cage consisting of bars.

Anderson's contribution was to divide the screw into segments (Fig. 6a) separated by smooth rings (Fig. 6b) allowing the introduction of protrusions in front of these threadless parts to prevent the rotation of the material. The reduction in volume can come from reducing the diameter of the cage, increasing the diameter of the core, reducing the pitch of the screws. Smooth rings have a variable taper.

Screw core: the main shaft around which the screw thread wraps. The diameter of the core and the diameter of the cage define the gap through which the material is forced to pass.

Screw thread: metal strip wrapped around the core to form a helix whose rotation allows to transmit an axial movement to the material provided that the frictional force between the material and the cage is greater than the rotational driving force of the screw movement.

Knives (Fig. 6c): protrusions from the cage to the core of the screw located in areas where the thread is interrupted to block the rotation of the material.

Cold pressing: technique consisting in pressing the seeds without thermal pretreatment. It should be noted that the concept of cold pressing does not imply a guarantee that the temperature will not rise during pressing. Because of the mechanical work and friction, the solid can undergo a rather important rise in temperature going from 40 to $100^{\circ} \mathrm{C}$ for the most common seeds. This temperature rise is generally much less pronounced for oil, the largest volume of which comes out of the sections of the press where the temperature is lowest.

\section{Supplementary Material}

Supplementary Material S1. Supplementary Material S2.

The Supplementary Material is available at http://www.ocljournal.org/10.1051/ocl/2021048/olm.

\section{References}

Akinoso R, Raji AO, Igbeka JC. 2009. Effects of compressive stress, feeding rate and speed of rotation on palm kernel oil yield. Journal of Food Engineering 93(4): 427-430.

Bako T, Enyi OS, Imolemhe UV. 2020. Mathematical modeling of mechanical horizontal screw oil extractor. Agricultural Engineering International: CIGR Journal 22(2): 244-254.

Bargale PC, Sosulski K, Sosulski FW. 2000. Enzymatic hydrolysis of soybean for solvent and mechanical oil extraction. Journal of Food Process Engineering 23(4): 321-327.

Bogaert L. 2017. Étude et modélisation du pressage continu des graines oléagineuses. Doctoral dissertation. Compiègne.

Bogaert L, Mathieu H, Mhemdi H, Vorobiev E. 2018. Characterization of oilseeds mechanical expression in an instrumented pilot screw press. Industrial Crops and Products 121: 106-113.

Bouallegue K, Allaf T, Van CN, Ben R. 2016. Impact of texturing/ cooling by Instant controlled pressure drop DIC on pressing and/ or solvent extraction of vegetal oil. Int J Eng Res 2(1): 12.

Carré P. 2021. Naturalness in the production of vegetable oils and proteins. OCL 28: 10.

Chapuis A, Blin J, Carré P, Lecomte D. 2014. Separation efficiency and energy consumption of oil expression using a screw-press: the case of Jatropha curcas L. seeds. Industrial Crops and Products 52: 752-761.

Deli S, Masturah FM, Aris TY, Nadiah WW. 2011. The effects of physical parameters of the screw press oil expeller on oil yield from Nigella sativa L seeds. International Food Research Journal 18(4): 1367. 
Demarco A, Gibon V. 2020. Overview of the soybean process in the crushing industry. OCL 27: 60 .

Dufaure C, Leyris J, Rigal L, Mouloungui Z. 1999. A twin-screw extruder for oil extraction: I. Direct expression of oleic sunflower seeds. Journal of the American Oil Chemists' Society 76(9): 1073-1079.

Evangelista RL. 2009. Oil extraction from lesquerella seeds by dry extrusion and expelling. Industrial Crops and Products 29(1): 189-196.

Evangelista RL, Cermak SC. 2007. Full-press oil extraction of cuphea (PSR23) seeds. Journal of the American Oil Chemists' Society 84 (12): 1169-1175.

Fadhlullah M, Widiyanto SNB, Restiawaty E. 2015. The potential of nyamplung (Calophyllum inophyllum L.) seed oil as biodiesel feedstock: effect of seed moisture content and particle size on oil yield. Energy Procedia 68: 177-185.

Fakayode OA, Ajav EA. 2019. Development, testing and optimization of a screw press oil expeller for moringa (Moringa oleifera) seeds. Agricultural Research 8(1): 102-115.

Florapower. 2021. Peeled seeds pressing. Available from https:// www.florapower.de/en/technologies/peeled-seeds-pressing/ (last consult, May 2021).

Gunstone FD. 2011. Production and trade of vegetable oils. Vegetable oils in food technology: composition, properties and uses (2, 1-21). John Wiley \& Sons, 376 p.

Herak D, Gurdil G, Sedlacek A, Dajbych O, Simanjuntak S. 2010. Energy demands for pressing Jatropha curcas L. seeds. Biosystems Engineering 106(4): 527-534.

Ibrahim SM, Abed KA, Gad MS, Hashish HA. 2017. Optimum oil yield from Egyptian Jatropha seeds using screw press. Int J Mech Mechatron Eng 17(1): 47-56.

Kabutey A, Herak D, Ambarita H, Sigalingging R. 2019. Modeling of linear and non-linear compression processes of sunflower bulk oilseeds. Energies 12(15): 2999.

Kabutey A, Herak D, Mizera C, Hrabe P. 2018. Mathematical description of loading curves and deformation energy of bulk oil palm kernels. Agronomy Research 16(4): 1686-1697.

Karaj S, Müller J. 2011. Optimizing mechanical oil extraction of Jatropha curcas L. seeds with respect to press capacity, oil recovery and energy efficiency. Industrial Crops and Products 34 (1): 1010-1016.

Kartika IA, Pontalier PY, Rigal L. 2005. Oil extraction of oleic sunflower seeds by twin screw extruder: influence of screw configuration and operating conditions. Industrial Crops and Products 22(3): 207-222.

Khan LM, Hanna MA. 1983. Expression of oil from oilseeds-a review. Journal of Agricultural Engineering Research 28(6): 495-503.

Lanoisellé JL, Vorobyov EI, Bouvier JM, Pair G. 1996. Modeling of solid/liquid expression for cellular materials. AIChE Journal 42 (7): 2057-2068.

Le Cadre P, Pressenda F, Labalette F, Peyronnet C. 2015. Valorisation de tourteaux de soja issus d'une production locale non OGM chez les fabricants d'aliments. OCL 22(5): D507.

Li S, Zhang Y, Liu X. 2010. Development of a twin-screw oil press with double-step multiple-stage squeezing chamber. Transactions of the Chinese Society of Agricultural Engineering 26(8): 102-107.

Li W, Huang F, Gu Q, Gan W. 2007. Research and application of twinscrew expeller for cold pressing of de-hulled rapeseed. In: The 12th International Rapeseed Congress, Wuhan, China. USA: Science Press, pp. 213-216.

Liu R, Xiao Z, Li C, et al. 2017. Calculation of equivalent friction coefficient for castor seed by single screw press. In: IOP
Conference Series: Earth and Environmental Science. IOP Publishing, Vol. 81, No. 1, p. 012185.

Martínez ML, Marín MA, Faller CMS, Revol J, Penci MC, Ribotta PD. 2012. Chia (Salvia hispanica L.) oil extraction: study of processing parameters. LWT-Food Science and Technology 47(1): 78-82.

Moreau RA, Johnston DB, Hicks KB. 2005. The influence of moisture content and cooking on the screw pressing and prepressing of corn oil from corn germ. Journal of the American Oil Chemists' Society 82(11): 851-854.

Mridula D, Saha D, Gupta RK, Bhadwal S. 2019. Oil expelling of dehulled sunflower: Optimization of screw pressing parameters. Journal of Food Processing and Preservation 43(1): e13852.

Murase T, Iwata M, Wakita M, Adachi T, Hayashi N, Shirato M. 1987. Variable-pressure/variable rate expression of semisolid materials. J Chem Eng Jpn 20: 603-608.

Naeem MA, Hashish HA, Zahran HA. 2017. Optimize the Roselle (Hibiscus sabdariffa L.) seeds oil extraction using screw press. Egypt J Nutr 32(4): 29-48.

Olayanju TA, Akinoso R, Oresanya MO. 2006. Effect of wormshaft speed, moisture content and variety on oil recovery from expelled beniseed. Agricultural Engineering International: CIGR Journal 8.

Patil RT, Ali N. 2006. Effect of pre-treatments on mechanical oil expression of soybean using a commercial oil expeller. International Journal of Food Properties 9(2): 227-236.

Pedretti EF, Del Gatto A, Pieri S, et al. 2019. Experimental study to support local sunflower oil chains: production of cold pressed oil in Central Italy. Agriculture 9(11): 1-12.

Rombaut N, Savoire R, Thomasset B, Castello J, Van Hecke E, Lanoisellé JL. 2015. Optimization of oil yield and oil total phenolic content during grape seed cold screw pressing. Industrial Crops and Products 63: 26-33.

Sarkis JR, Boussetta N, Tessaro IC, Marczak LDF, Vorobiev E. 2015. Application of pulsed electric fields and high voltage electrical discharges for oil extraction from sesame seeds. Journal of Food Engineering 153: 20-27.

Shilong L, Xiefang L. 2011. Cold-pressed oil extraction of camellia seeds. In: 2011 International Conference on New Technology of Agricultural. IEEE, pp. 135-138.

Shirato M, Iwata M, Wakita M, Murase T, Hayashi N. 1987. Constantrate expression of semisolid materials. J Chem Eng Jpn 20: 1-6.

Sigalingging R, Herák D, Kabutey A, Čestmír M, Divišová M. 2014. Tangent curve function description of mechanical behaviour of bulk oilseeds: a review. Scientia Agriculturae Bohemica 45(4): 259-264.

Singh KK, Wiesenborn D, Kangas N, Tostenson K. 2002a. Characterization of preparation parameters for improved screw pressing of crambe seed. Transactions of the ASAE 45(4): 1029.

Singh KK, Wiesenborn DP, Tostenson K, Kangas N. 2002b. Influence of moisture content and cooking on screw pressing of crambe seed. Journal of the American Oil Chemists' Society 79(2): 165-170.

Singh KK, Wiesenborn D, Kangas N, Tostenson K. 2004. Screw pressing characteristics of dehulled crambe seed. Transactions of the ASAE 47(1): 199.

Soto C, Chamy R, Zuniga ME. 2007. Enzymatic hydrolysis and pressing conditions effect on borage oil extraction by cold pressing. Food Chemistry 102(3): 834-840.

Tostenson K, Wiesenborn D, Lipp D, Kangas N, Zheng Y. 2004. Startup approaches and performance monitoring for screw-pressing flaxseed oil. In: 2004 ASAE Annual Meeting. American Society of Agricultural and Biological Engineers, p. 1.

Turkay S, Gurbuz H. 2013. A new strategy for edible vegetable oil production. Lipid Technology 25(1): 11-13. 
Uitterhaegen E, Evon P. 2017. Twin-screw extrusion technology for vegetable oil extraction: a review. Journal of Food Engineering 212: 190-200.

Uquiche E, Jeréz M, Ortíz J. 2008. Effect of pretreatment with microwaves on mechanical extraction yield and quality of vegetable oil from Chilean hazelnuts (Gevuina avellana $\mathrm{Mol}$ ). Innovative Food Science \& Emerging Technologies 9(4): 495-500.

Vadke VS, Sosulski FW. 1988. Mechanics of oil expression from canola. Journal of the American Oil Chemists' Society 65(7): 1169-1176.

Venkitasamy C, Teh HE, Atungulu GG, McHugh TH, Pan Z. 2014. Optimization of mechanical extraction conditions for producing grape seed oil. Transactions of the ASABE 57(6): 1699-1705.

Ward JA. 1976. Processing high oil content seeds in continuous screw presses. Journal of the American Oil Chemists' Society 53(6): 261-264.
Wiesenborn D, Doddapaneni R, Tostenson K, Kangas N. 2001. Cooking indices to predict screw-press performance for crambe seed. Journal of the American Oil Chemists' Society 78(5): 467-471.

Willems P, Kuipers NJM, De Haan AB. 2008. Hydraulic pressing of oilseeds: experimental determination and modeling of yield and pressing rates. Journal of Food Engineering 89(1): $8-16$.

Zdanowska P, Dróżdż B, Janakowski S, Derewiaka D. 2019. Impact of preliminary ultrasound treatment of rape seeds on the pressing process and selected oil characteristics. Industrial Crops and Products 138: 111572.

Zheng YL, Wiesenborn DP, Tostenson K, Kangas N. 2003. Screw pressing of whole and dehulled flaxseed for organic oil. Journal of the American Oil Chemists' Society 80(10): 1039-1045.

Cite this article as: Carré P. 2022. New approach for the elucidation of the phenomena involved in the operation of vegetable oil extraction presses. OCL 29: 6. 